\title{
Synergistic Antifungal Effect of Fluconazole Combined with Licofelone against Resistant Candida albicans
}

\author{
Xinning Liu'1,2, Tao Li³, Decai Wang ${ }^{1}$, Yilei Yang ${ }^{4}$, Wenwen Sun ${ }^{1}$, Jianqiao Liu' ${ }^{5}$ and \\ Shujuan Sun ${ }^{4 *}$
}

'Department of Clinical Pharmacy, Taishan Medical University, Taian, China, ${ }^{2}$ Department of Microbial and Biochemical Pharmacy, School of Medicine and Pharmacy, Ocean University of China, Qingdao, China, ${ }^{3}$ Intensive Care Unit, Qianfoshan Hospital Affiliated to Shandong University, Jinan, China, ${ }^{4}$ Department of Pharmacy, Qianfoshan Hospital Affiliated to Shandong University, Jinan, China, ${ }^{5}$ General Practice, Shandong Provincial Hospital, Jinan, China

\section{OPEN ACCESS}

Edited by:

Jack Wong,

The Chinese University of Hong Kong, Hong Kong

Reviewed by: Taissa Vila,

University of Texas at San Antonio,

United States

Chaminda Jayampath Seneviratne, National University of Singapore, Singapore

*Correspondence: Shujuan Sun sunshujuan888@163.com

Specialty section: This article was submitted to Antimicrobials, Resistance and Chemotherapy,

a section of the journal

Frontiers in Microbiology

Received: 04 August 2017 Accepted: 13 October 2017 Published: 07 November 2017

Citation:

Liu X, Li T, Wang D, Yang Y, Sun W,

Liu J and Sun S (2017) Synergistic Antifungal Effect of Fluconazole Combined with Licofelone against Resistant Candida albicans.

Front. Microbiol. 8:2101. doi: 10.3389/fmicb.2017.02101
Candida albicans (C. albicans) is one of the important opportunistic fungal pathogens that is closely associated with disseminated or chronic infections. The objective of this study is to evaluate the synergistic antifungal effect of licofelone, which is dual microsomal prostaglandin E2 synthase/lipoxygenase (mPGES-1/LOX) inhibitor in combination with fluconazole against $C$. albicans. Here our results showed that licofelone $(16 \mu \mathrm{g} / \mathrm{mL})$ can synergistically work with fluconazole $(1 \mu \mathrm{g} / \mathrm{mL})$ against planktonic cells of fluconazole-resistant $C$. albicans. The two-drug combination inhibited the $C$. albicans biofilm formation over $12 \mathrm{~h}$, and reduced the expression of extracellular phospholipase genes, biofilm-specific genes and RAS/cAMP/PKA pathway related genes. In addition, the two-drug combination inhibited the transition from yeast to hyphal growth form, and decreased the secreted aspartyl proteinase activity, while not affecting the drug efflux pumps activity. Galleria mellonella model was also used to confirm the antifungal activity of the drug combination in vivo. This study first indicates that the combination of fluconazole and licofelone has synergistic effect against resistant C. albicans and could be a promising therapeutic strategy for the antifungal treatment.

Keywords: biofilms, cyclooxygenase (COX), drug resistance mechanisms, enzyme inhibitor, phospholipase

\section{INTRODUCTION}

Candida albicans is one of the important fungal pathogens that forms biofilm on the surface of catheters and other medical devices. It is also believed to be mainly implicated in disseminated or chronic fungal infections in ill and immunocompromised individuals (Carrillo-Munoz et al., 2006). Currently, the antifungal drugs used in a clinical practice include azoles, amphotericin $\mathrm{B}$, and echinocandins. Amphotericin $\mathrm{B}$ is a potent antifungal agent against an array of yeast and filamentous fungal pathogens, however, the application is limited by the significant toxicities such as renal toxicity, infusion reactions, and hepatotoxicity (Clements and Peacock, 1990). Both amphotericin B and echinocandin drugs also have minimal gastrointestinal absorption and are only available as parenteral formulations, while fluconazole, one of the commonly used first-line drug of the azole family in clinical prevention and treatment of Candida infections, is readily absorbed with high bioavailability (Nett and Andes, 2016). The wide-spread use of antifungal drugs 
has increased the incidence of candida-resistance, ultimately leading to refractory fungal infections (Chen et al., 2012; Pfaller et al., 2015). In the United States, fluconazole-resistance has caused significant additional hospitalization costs and deaths (Sagatova et al., 2015). Therefore, seeking novel agent combined with fluconazole against resistant $C$. albicans is a urgent need.

Licofelone, a dual mPGES-1/LOX inhibitor is the terminal enzyme in the biosynthesis of Prostaglandin E2 $\left(\mathrm{PGE}_{2}\right)$. Previous studies have noted that $\mathrm{PGE}_{2}$, as the final product of arachidonic acid metabolic pathway can mediate several biological phenomena (Harizi et al., 2008). It is also associated with the ability of $C$. albicans to switch between yeast and hyphal growth forms. Recent studies indicated that $\mathrm{PGE}_{2}$ synthesized from host and fungal can promote cell adhesion, germ tube formation and enhance fungal resistance in C. albicans (Kalo-Klein and Witkin, 1990; Noverr et al., 2001). RAS/cAMP/PKA pathway is important for mediating the transition from yeast to hyphal growth form in C. albicans and is known to regulate the expression of many biofilmspecific genes including EFG1, BCR1, ALS1, ALS3, and HWP1 (Hogan and Sundstrom, 2009). Latest study shows that $\mathrm{PGE}_{2}$ increased cAMP level, activated PKA in C. albicans-infected macrophages, and therefore stimulated $C$. albicans germ tube formation (Yun et al., 2016). Based on this, we hypothesize that the regulation of $\mathrm{PGE}_{2}$ influencing biofilm formation may be associated with the RAS/cAMP/PKA pathway. In several studies, the synergistic effects of cyclooxygenase (COX) inhibitors combined with antifungal drugs against $C$. albicans biofilm and planktonic cells have been observed. These potential antifungal activities are supposed to be associated with the regulation of $\mathrm{PGE}_{2}$ production (Alem and Douglas, 2004; de Quadros et al., 2011; Rusu et al., 2014; Liu et al., 2016). A dual mPGES-1/LOX inhibitor, licofelone can suppress $\mathrm{PGE}_{2}$ formation (Koeberle et al., 2008) and has recently succeeded in reaching the required criteria in phase III clinical trials for osteoarthritis (Payandemehr et al., 2015), but no researches in regards with its antifungal activity and mechanism against planktonic and biofilm cells of C. albicans have been carried out so far.

In this study, we first evaluated the in vitro efficacy of licofelone alone and in combination with fluconazole against C. albicans by the checkerboard microdilution method, and observed their antimicrobial effects on biofilm formation. In addition, the toxicity of $C$. albicans treatment was investigated by Galleria mellonella model in vivo, survival analysis, and histology. The fungal burden determination was used to confirm the antifungal effect of combined treatment during C. albicans infections. Related antifungal mechanisms were also explored in this study. Various virulence factors, other than biofilm formation, have been contributed to C. albicans pathogenicity in the hosts, such as secreted aspartyl proteinase and phospholipase activity (Garcia-Vidal et al., 2013; Cui et al., 2015). Aspartyl proteinase secreted from $C$. albicans is directly related to virulence properties such as adhesion, tissue invasion and immune evasion (Braga-Silva and Santos, 2011). C. albicans produces phospholipases, which can destroy cell membranes during host cell invasion (Ghannoum, 2000). It has been shown that phosphatidylcholine-specific phospholipase D1 is important for yeast to hyphal transitions under certain conditions in C. albicans (Hube et al., 2001). The gene expression levels including RAS/cAMP/PKA pathway related genes (RAS1, CYR1, TPK2), biofilm-specific related genes (EFG1, BCR1, ALS1, $A L S 3, H W P 1)$, and secreted aspartyl proteinase (SAP) genes (SAP1, SAP2, SAP3, SAP4) were assessed by RT-PCR. The morphogenesis of $C$. albicans was also observed by fluorescence microscope. We also detected the effect of the two-drug combination on extracellular phospholipase activities by egg yolk agar method and measured the drug efflux pumps activity by rhodamine $6 \mathrm{G}$ assay.

\section{MATERIALS AND METHODS}

\section{Strains and Media}

Eight clinical isolates were obtained from Shandong Qianfoshan Hospital in China. Six resistant strains, Candida albicans (CA10, CA16), Candida glabrata (CG2, CG3) and Candida parapsilosis (CP2, CP3); and two sensitive strains, Candida albicans (CA4, CA8) were used in this study. Their susceptibilities were determined according to Clinical and Laboratory Standards Institute document M27-A3 (Wayn, 2008) with C. albicans (ATCC 10231) as the quality control strain. The strains were maintained at $-80^{\circ} \mathrm{C}$ and subcultured at least twice on the yeast-peptone-dextrose (YPD) solid medium at $35^{\circ} \mathrm{C}$. Licofelone and fluconazole were purchased from Shanghai Boylechem Co., Ltd., China and Dalian Meilun Biotech Co., Ltd., China, respectively. The stock solution was prepared according to the manufacturer's instructions. Briefly, fluconazole was dissolved in sterile deionized water at room temperature, and licofelone was dissolved in dimethyl sulfoxide (DMSO) with $0.2 \%$ Tween 80 . Each stock solution was prepared at a final concentration of $2560 \mu \mathrm{g} / \mathrm{mL}$ and stored at $-20^{\circ} \mathrm{C}$ until needed. RPMI1640 was used as a diluent medium for drugs and strains. The minimal inhibitory concentration (MIC) was defined as the lowest concentration of the drug that inhibited fungal growth by $80 \%$ (MIC80) compared with that of the growth control and sessile MIC (sMIC) was read as the lowest concentration that produced a 50\% reduction in growth compared with that of the drug-free control. Before conducting the large number of experiments, the MIC and sMIC of which fluconazole and licofelone used alone in the experiments was first evaluated as a preliminary experiment.

\section{MIC Determination by Broth Microdilution Assays}

The MICs of licofelone and fluconazole against C. albicans strains were determined by the broth microdilution method according to the Clinical and Laboratory Standards Institute (CLSI) standard M27-A3 (Lockhart et al., 2011). For the checkerboard assays (Kuykendall and Lockhart, 2016), the final concentration of fluconazole and licofelone used were $0.125-64 \mu \mathrm{g} / \mathrm{mL}$ and 2-128 $\mu \mathrm{g} / \mathrm{mL}$, respectively, for resistant candida strains (CA10, CA16, CG2, CG3, CP2, CP3); and 0.03125-16 $\mu \mathrm{g} / \mathrm{mL}$ and 
2-128 $\mu \mathrm{g} / \mathrm{mL}$, respectively, for sensitive candida strains (CA4, CA8). All drugs were diluted in $50 \mathrm{ml}$ sterile RPMI 1640 medium. Fluconazole and licofelone were added to the wells in the second to eleventh columns and A through $G$ lines of the 96-well plate, respectively. $100 \mu \mathrm{l}$ of $C$. albicans cell suspensions $\left(0.5 \sim 2.5 \times 10^{3}\right.$ cells $\left./ \mathrm{mL}\right)$ were then inoculated into each well of 96-well plates. Each wells were filled with RPMI-1640 to a final volume of $200 \mu \mathrm{l}$ except the control plate. Negative controls were performed in $200 \mu \mathrm{l} \mathrm{RPMI1640}$ in A12-H12 wells, and growth controls were performed in $100 \mu \mathrm{l}$ RPMI1640 and $100 \mu \mathrm{l}$ microorganisms in the H1 well. The plate was incubated at $35^{\circ} \mathrm{C}$ for $24 \mathrm{~h}$. Both visual reading and optical density (OD) were performed to determine the MIC value (Bertout et al., 2011). OD was measured on the absorbance at $492 \mathrm{~nm}$ on a microplate reader. MIC endpoints were defined as the lowest concentration of drugs causing $80 \%$ decrease in viability compared to the drug-free control (MIC80). All experiments were performed in triplicate. Drug interactions were interpreted by the fractional inhibitory concentration index (FICI) model and the percentage of growth difference $(\Delta \mathrm{E})$ model. The FICI $\leq 0.5$ represents synergy, FICI $0.5<$ FICI $\leq 4$ represents no interaction, and FICI $>4.0$ represents antagonism (Odds, 2003). The $\Delta \mathrm{E}$ model was defined by the following equation: $\Delta \mathrm{E}=\mathrm{E}_{\text {predicted }}-\mathrm{E}_{\text {measured. }}$. The $\mathrm{E}$ value was calculated by the data obtained directly from experiments. Statistically significant interactions of $<100 \%$ were considered weak, those from 100 to $200 \%$ were considered moderate, and those of $>200 \%$ were considered strong, as previously described (Katragkou et al., 2015).

\section{sMIC Determination by Broth Microdilution Assays}

Candida albicans biofilm was developed using a slightly modified method described above (Gu et al., 2016; Sun et al., 2017). The sMICs of fluconazole and licofelone against C. albicans (CA10, CA16, CA4, CA8) biofilms were tested. The biofilms were formed over three time intervals $(8,12$, and $24 \mathrm{~h})$ at $35^{\circ} \mathrm{C}$ by pipetting $100 \mathrm{ml}$ of the standardized cell suspension $\left(10^{3}\right.$ cells $\left./ \mathrm{mL}\right)$ into selected wells of 96-well plate. After each adhesion phase $(8,12$, and $24 \mathrm{~h})$, the cell suspensions were gently washed three times with sterile phosphate-buffered saline (PBS) and the planktonic yeast were removed. Fluconazole and licofelone were then added to the corresponding wells of 96-well plate in serially double-diluted concentrations. The final concentration of fluconazole and licofelone in wells was ranged from $1-512 \mu \mathrm{g} / \mathrm{mL}$ and $2-128 \mu \mathrm{g} / \mathrm{mL}$ for each isolate, respectively. The control wells were filled with $200 \mu \mathrm{l}$ RPMI 1640 only. The plates were then incubated for another $24 \mathrm{~h}$ at $35^{\circ} \mathrm{C}$ in an orbital shaker. A colorimetric reduction assay was carried out with 2,3-bis-(2-methoxy-4-nitro-5-sulfophenyl)-2Htetrazolium-5-carboxanilide (XTT) according to the protocol of Melo et al. The absorbance was measured with a microtiter plate reader at the absorbance of $492 \mathrm{~nm}$, and the drug concentration that brought about a reduction in absorption by $50 \%$ contrasted to that in the control well was reported as the sMIC endpoint. Each test was performed in triplicate.

\section{Efficacy of Fluconazole and Licofelone in G. mellonella Infected with C. albicans by Survival Assay}

Galleria mellonella in the final instars larval stage of development was used as previously described with some modifications (Mylonakis et al., 2005; Amorim-Vaz et al., 2015). Larvae were divided into four groups: growth control group (PBS only), fluconazole $(160 \mu \mathrm{g} / \mathrm{mL})$ treated group, licofelone $(80 \mu \mathrm{g} / \mathrm{mL})$ treated group, and fluconazole $(160 \mu \mathrm{g} / \mathrm{mL})$ with licofelone $(80 \mu \mathrm{g} / \mathrm{mL})$ treated group. Control group of larvae inoculated was studied in parallel in every infection investigation. The larvae were stored in wood shavings in petri dishes at $35^{\circ} \mathrm{C}$ in the dark condition for 2 days before the experiments. Larvae with dark spots or apparent melanization were excluded. Resistant C. albicans isolates (CA10) were grown overnight on liquid Sabouraud medium, and the inocula were suspended in PBS buffer supplemented with $20 \mu \mathrm{g} / \mathrm{mL}$ of ampicillin to prevent bacterial contamination. $10 \mu \mathrm{l}$ of each larva suspension $\left(5 \times 10^{6}\right.$ cells $/ \mathrm{mL}$ ) were injected of through the last left proleg using a 10-1 syringe (Gaoge, China). The infected larvae were incubated at $35^{\circ} \mathrm{C}$ for $2 \mathrm{~h}$, and then treated with different group of antifungal drugs. The death of larvae was monitored by visual inspection of their color (brown-dark brown) each $24 \mathrm{~h}$ for 4 days. The survival experiments were terminated at 4 days after infection. Each experiment groups contained 20 larvae (0.2-0.25 g in weight) and the experiment was repeated three times using larvae from different batches.

\section{Fungal Burden Determination}

Fungal burden was determined by colony-forming unit (CFU) counts for 4 days after infection (Krezdorn et al., 2014). Larvae were divided into four groups: growth control group (PBS only), fluconazole $(160 \mu \mathrm{g} / \mathrm{mL})$ treated group, licofelone $(80 \mu \mathrm{g} / \mathrm{mL})$ treated group, and fluconazole $(160 \mu \mathrm{g} / \mathrm{mL})$ with licofelone $(80 \mu \mathrm{g} / \mathrm{mL})$ treated group. Each larva was infected with $5 \times 10^{6}$ cells/larva of resistant C. albicans (CA10) and incubated at $35^{\circ} \mathrm{C}$ for $2 \mathrm{~h}$, then treated with different drug. At every $24 \mathrm{~h}, 3$ larvae from each group were selected with no discrimination, suspended in $1 \mathrm{ml}$ of PBS-ampicillin, and gently homogenized for a few seconds. The mix was 10 -fold diluted with PBS buffer and $10 \mu \mathrm{l}$ of these dilutions were inoculated on the sabouraud agar plates. The plates were incubated at $35^{\circ} \mathrm{C}$ for $24 \mathrm{~h}$ and the number of CFUs was counted. The results were expressed as mean standard deviation (SD). Each experiment group contained 20 larvae (0.2-0.25 g in weight) and experiment was repeated three times using larvae from different batches.

\section{Histological Study}

To evaluate the presence of resistant C. albicans (CA10) in tissue of G. mellonella, three larvae from different groups (infected only; and infected and treated with licofelone, fluconazole and licofelone-fluconazole) were collected at day 3 after infection. The larvae were preserved in $70 \%$ ethanol and cut into 8 - $\mu \mathrm{m}$-thick sections using a cryostat. The samples were dried naturally at room temperature for 2 days, stained with Periodic Acid Schiff reagent (PAS), and dehydrated with increasing concentrations 
of ethanol and xylol (70, 80, 90, 96, and 100\%). Finally, the samples were fixed in neutral balata and dried naturally at room temperature for 2 days. The stained tissues were observed under an Olympus FSX100 fluorescence microscope with $\times 4.2$ objectives. The experiment was repeated three times using larvae from different batches.

\section{Phospholipase Activity of C. albicans Treated with Licofelone}

Phospholipase activity of resistant C. albicans (CA10) treated with different drugs was detected by egg yolk agar plate method with some modifications (Niewerth and Korting, 2001). The egg yolk medium consisted of $15 \mathrm{~g} / \mathrm{L}$ peptone, $3 \mathrm{~g} / \mathrm{L}$ beef extract ointment, $5 \mathrm{~g} / \mathrm{L} \mathrm{NaCl}, 15 \mathrm{~g} /$ liter agar, $10 \mathrm{~g} / \mathrm{L}$ glucose, and $10 \%$ sterile egg yolk emulsion. Each culture with $10^{7} \mathrm{CFU} / \mathrm{mL}$ were treated with different drug group including fluconazole (1 $\mu \mathrm{g} / \mathrm{mL})$ group, licofelone $(16 \mu \mathrm{g} / \mathrm{mL}$ or $32 \mu \mathrm{g} / \mathrm{mL})$ group, fluconazole $(1 \mu \mathrm{g} / \mathrm{mL})$ combined with licofelone $(16 \mu \mathrm{g} / \mathrm{mL}$ or $32 \mu \mathrm{g} / \mathrm{mL}$ ) group, and growth control (drug-free) group, transferred into separate eppendorf tubes, and then incubated at $35^{\circ} \mathrm{C}$ for $24 \mathrm{~h}$. Then, $10 \mu \mathrm{l}$ suspension of each tubes were inoculated onto the medium, the plates were incubated at $35^{\circ} \mathrm{C}$ for $72 \mathrm{~h}$. The diameter of the precipitation zone (a) and the diameter of the precipitation zone plus the diameter of the colony (b) were measured. Phospholipase zone $(\mathrm{Pz})$ was designated as $\mathrm{Pz}=\mathrm{a} / \mathrm{b}$, as described above. According to this definition, phospholipase index was scored and categorized as follows: negative $(\mathrm{Pz}=1)$; very low $(\mathrm{Pz}=0.90$ to 0.99$)$; low $(\mathrm{Pz}=0.80$ to 0.89$)$; high $(\mathrm{Pz}=0.70$ to 0.79$)$, and very high $(\mathrm{Pz} \leq 0.69)$, as previously reported (Price et al., 1982). Each experiment was tested in triplicate and the phospholipase activity value was recorded as the average of the 3 measurements.

\section{Real-Time Quantitative PCR}

mRNA expression of secreted aspartyl proteinase-related genes (SAP1, SAP2, SAP3, and SAP4), RAS/cAMP/PKA pathway related genes (RAS1, CYR1, TPK2), and biofilm formation related genes (EFG1, BCR1, HWP1, ALS1, ALS3) was measured by RT-PCR. Resistant C. albicans (CA10) cells were grown to midlog phase in RPMI-1640 medium at $35^{\circ} \mathrm{C}$ after treatment with fluconazole $(1 \mu \mathrm{g} / \mathrm{mL})$ alone group, licofelone $(16 \mu \mathrm{g} / \mathrm{mL})$ alone group and fluconazole $(1 \mu \mathrm{g} / \mathrm{mL})$ combined with licofelone (16 $\mu \mathrm{g} / \mathrm{mL}$ ) group. Cultures without drugs were served as controls. Total RNA was extracted and isolated from cells using RNA pure yeast kit (DNase I) (CWBiotech, Beijing, China). A diluted RNA was reverse transcribed to cDNA using firststrand cDNA synthesis Super Mix kit (CWBiotech) at $42^{\circ} \mathrm{C}$ for $30 \mathrm{~min}$ following $85^{\circ} \mathrm{C}$ for $5 \mathrm{~min}$ according to the manufacturer's instructions. RT-PCR reactions were performed using CDNA, ultra SYBR mixture (with ROX) (CWBiotech), and primers with an ABI ViiA 7 (Applied Biosystems) sequence detection system (CWBiotech). An aliquot of $25 \mu \mathrm{l}$ PCR mix was used for each gene and the cycling conditions were $95^{\circ} \mathrm{C}$ for $10 \mathrm{~min}$, followed by 40 cycles of $95^{\circ} \mathrm{C}$ for $15 \mathrm{~s}$ and $60^{\circ} \mathrm{C}$ for $1 \mathrm{~min}$. ACT1 was found to be performed well under all experimental conditions, therefore, in this study, ACT1 was chosen to be suitable for use as an endogenous control gene (Cao et al., 2012; Bu et al., 2016). Primers used in this study are in Supplementary Table S1. The experiment was repeated on 3 independent occasions.

\section{C. albicans Morphogenesis Analysis}

The morphogenesis analysis was carried out as described before (Pierce et al., 2015). The cells of resistant C. albicans (CA10) were grown overnight at $30^{\circ} \mathrm{C}$ in RPMI1640 and treated with different drugs including growth control (drug-free) group, fluconazole $(1 \mu \mathrm{g} / \mathrm{mL})$ group, licofelone $(16 \mu \mathrm{g} / \mathrm{mL})$ group, and fluconazole (1 $\mu \mathrm{g} / \mathrm{mL})$ combined with licofelone $(16 \mu \mathrm{g} / \mathrm{mL})$ group in the well plates. The treated suspensions were then examined by fluorescence microscope to determine the percentage of hyphal formation. The experiment was repeated on 3 independent occasions.

\section{Rhodamine 6G Efflux Assays}

The determination of the functional activity of drug efflux pumps affected by licofelone was carried out (Sun et al., 2015). Briefly, resistant C. albicans (CA10) cells were shaken overnight at $35^{\circ} \mathrm{C}$ in YPD broth and then washed three times with PBS. The cells were harvested by centrifugation and adjusted to $1 \times 10^{7}$ cells/ml in PBS. In order to assess the efflux of Rh6G, we set 2 groups in this experiment: growth control group (drug-free) and licofelone $(16 \mu \mathrm{g} / \mathrm{mL})$ group. Rhodamine 6G (final concentration of $10 \mu \mathrm{M}$ ) was added to each cell suspension. After incubating $55 \mathrm{~min}$ at $35^{\circ} \mathrm{C}, \mathrm{C}$. albicans cells were collected by centrifuging at 3,000 rpm for $5 \mathrm{~min}$, washed three times with PBS, and resuspended with PBS containing 5\% glucose. Five hundred microlliter of each sample were withdrawn at every $10 \mathrm{~min}$. The mean fluorescent intensity (MFI) was immediately determined using the flow cytometer with excitation at $488 \mathrm{~nm}$ and emission at $530 \mathrm{~nm}$ at each specific time intervals. The experiment was repeated on 3 independent occasions.

\section{Statistical Analysis}

Data are presented as mean \pm SEM. All experiments were performed in triplicate. Graphs production, data distribution and statistical analyses were performed using Graph Pad Prism 5. After ensuring data conformed to a normal distribution, before and after data transformation, analysis of variance (ANOVA) and $t$-tests were used to investigate significant differences between independent groups. The G. mellonella survival curves were analyzed by the Kaplan-Meier method, and fungal burdens were analyzed using a $t$-test to measure statistical differences between two independent groups. $P<0.05$ was considered as statistically significant.

\section{RESULTS}

\section{MICs Determined by Broth Microdilution Assays}

The susceptibilities of 8 Candida isolates (CA4, CA8, CA10, CA16, CG2, CG3, CP2, CP3) were assessed under planktonic 

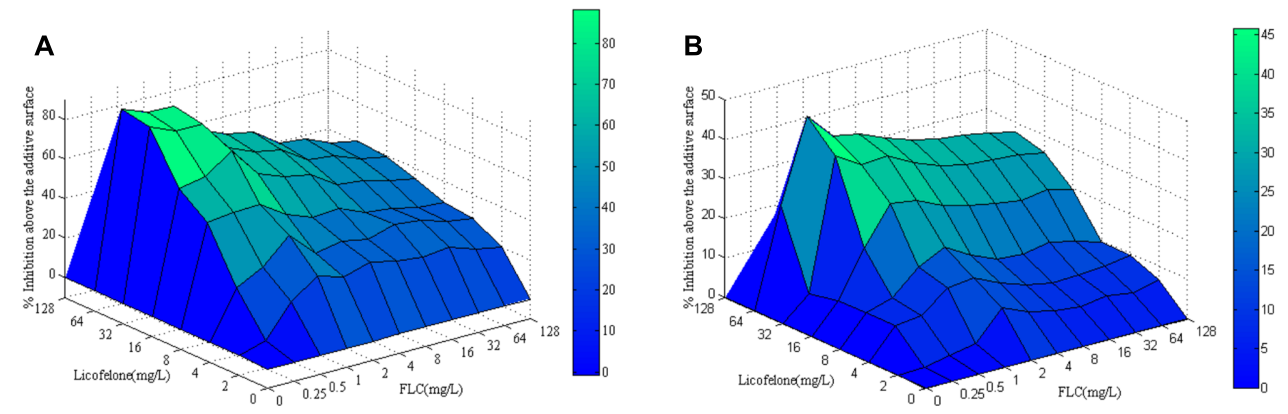

FIGURE 1 | Drug interactions of fluconazole and licofelone are interpreted by the $\Delta \mathrm{E}$ model. Three-dimensional plots of fluconazole combined with licofelone against Candida albicans were created by using MATLAB program. The concentrations of fluconazole and licofelone are depicted on the $x$ axis and $y$ axis, respectively, and the $E$-values obtained for each combination is depicted on the $z$ axis to construct a three-dimensional (3D) graphic. Peaks above the 0 plane represent synergistic combinations. The color-coding bar on the right indicates that the closer to the top of the bar, the more effective the drug combination. (A) The $\Delta \mathrm{E}$ model of Candida albicans10, (B) the $\Delta \mathrm{E}$ model of Candida albicans 16.

states. For all of the strains, the MIC of licofelone used alone was $128 \mu \mathrm{g} / \mathrm{mL}$, and the MICs of fluconazole alone were ranged from 1 to $512 \mu \mathrm{g} / \mathrm{ml}$ (Figures 1A,B). Susceptibility assay showed that the combination of licofelone and fluconazole has strong synergistic antifungal effects against resistant C. albicans: the $\mathrm{MIC}_{80}$ of fluconazole alone against resistant $C$. albicans (CA10, CA16) were $>512 \mu \mathrm{g} / \mathrm{mL}$, whereas when combined with licofelone $(16 \mu \mathrm{g} / \mathrm{mL})$, the MICs of fluconazole were decreased to 1 and 0.5 , respectively. These effects were also illustrated by the FICI in vitro: the FICI for the resistant C. albicans (CA10, CA16) strains is 0.127 and 0.250 , respectively (Table $\mathbf{1}$ ), however, the FICI of sensitive C. albicans (CA4, CA8) and non-albicans (CG2, CG3, CP2, CP3) strains were all $>0.5$, indicating that the two-drug combination exhibited no antifungal activity against the sensitive $C$. albicans and non-albicans. These results were also interpreted by $\Delta \mathrm{E}$ method.

\section{sMIC Determined by Broth Microdilution Assays}

The susceptibilities of 4 C. albicans (CA4, CA8, CA10, CA16) isolates were assessed under biofilm states. For the resistant
C. albicans (CA10, CA16) and sensitive C. albicans (CA4, CA8), the sMIC of fluconazole and licofelone used alone was $512 \mu \mathrm{g} / \mathrm{mL}$ and $128 \mu \mathrm{g} / \mathrm{mL}$, respectively. The susceptibility test showed that licofelone $(16 \mu \mathrm{g} / \mathrm{mL})$ combined with fluconazole $(1 \mu \mathrm{g} / \mathrm{mL})$ had synergistic antifungal effects against C. albicans biofilms (FICI $<0.5$ ) at both 8 and $12 \mathrm{~h}$ time point. However, after $12 \mathrm{~h}$ formation, the combined effect of fluconazole and licofelone on biofilm has gradually reduced. The combined antifungal effect was barely observed on the biofilm formed over $24 \mathrm{~h}$ with FICI $>1$, suggesting that the two-drug combination has synergistic antifungal effect at the early stage, but not the mature biofilm. The following experiments were performed in resistant $C$. albicans (CA10) isolate due to its strong susceptibility to the combination of licofelone and fluconazole. The SMICs of combined antifungal drugs are shown in Table 2.

\section{Efficacy of in G. mellonella Infected with C. albicans}

In vivo effect of fluconazole $(160 \mu \mathrm{g} / \mathrm{mL})$, licofelone $(80 \mu \mathrm{g} / \mathrm{mL})$, and their combination on infected G. mellonella treated was

TABLE 1 | The combined antifungal effects of fluconazole combined with licofelone against Candida albicans.

\begin{tabular}{|c|c|c|c|c|c|c|c|c|}
\hline \multirow[t]{2}{*}{ Drug } & \multirow[t]{2}{*}{ Strains } & \multicolumn{4}{|c|}{ MICs $(\mu \mathrm{g} / \mathrm{mL})$} & \multicolumn{2}{|c|}{ LA theory } & \multirow{2}{*}{$\begin{array}{c}\text { BI theory } \\
\Sigma S Y N\end{array}$} \\
\hline & & $\mathrm{MIC}_{\mathrm{A}}$ & $\mathrm{C}_{\mathrm{A}}$ & $\mathrm{MIC}_{\mathrm{B}}$ & $\mathrm{C}_{\mathrm{B}}$ & $\mathrm{FICl}$ & IN & \\
\hline \multirow[t]{8}{*}{ Fluconazole + Licofelone } & CA10 (R) & $>512$ & 1 & 128 & 16 & 0.127 & SYN & $2704 \%$ \\
\hline & CA16 (R) & $>512$ & 0.5 & 128 & 32 & 0.250 & SYN & $1112 \%$ \\
\hline & CA4(S) & 1 & 0.5 & 128 & 64 & 1.000 & $\mathrm{NI}$ & $<100 \%$ \\
\hline & CA8(S) & 2 & 1 & 128 & 64 & 1.000 & $\mathrm{NI}$ & $<100 \%$ \\
\hline & CG2 (R) & 128 & 32 & 128 & 64 & 0.750 & $\mathrm{NI}$ & $<100 \%$ \\
\hline & CG3 (R) & 64 & 16 & 128 & 64 & 0.750 & $\mathrm{NI}$ & $<100 \%$ \\
\hline & $\mathrm{CP} 2(\mathrm{R})$ & 128 & 2 & 128 & 64 & 0.516 & $\mathrm{NI}$ & $<100 \%$ \\
\hline & CP3 (R) & 128 & 4 & 128 & 64 & 0.531 & $\mathrm{NI}$ & $<100 \%$ \\
\hline
\end{tabular}

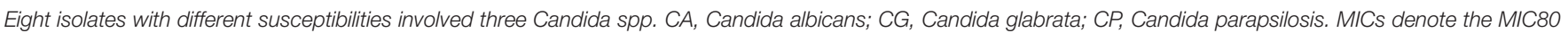

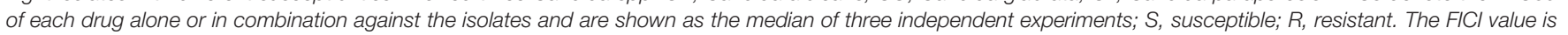
the median of three independent experiments; $\mathrm{FlCl} \leq 0.5$ for synergism, $\mathrm{FlCl}>4.0$ for antagonism and $0.5<\mathrm{FlCl} \leq 4.0$ for no interaction. 
TABLE 2 | Antifungal effect of fluconazole combined with licofelone against biofilm of resistant Candida albicans.

\begin{tabular}{|c|c|c|c|c|c|c|c|}
\hline \multirow[t]{2}{*}{ Strains } & \multirow[t]{2}{*}{ Times (h) } & \multicolumn{4}{|c|}{$\operatorname{SMIC}(\mu \mathrm{g} / \mathrm{mL})$} & \multicolumn{2}{|c|}{ LA theory } \\
\hline & & $\mathrm{MIC}_{\mathrm{A}}$ & $\mathrm{C}_{\mathrm{A}}$ & $\mathrm{MIC}_{\mathrm{B}}$ & $\mathrm{C}_{\mathrm{B}}$ & FICI & IN \\
\hline & 12 & $>512$ & 4 & $>128$ & 32 & 0.254 & SYN \\
\hline & 24 & $>512$ & 256 & $>128$ & 128 & $>1$ & $\mathrm{NI}$ \\
\hline CA16 (R) & 8 & $>512$ & 4 & 128 & 16 & 0.133 & SYN \\
\hline \multirow[t]{3}{*}{ CA4 (S) } & 8 & $>512$ & 8 & 128 & 16 & 0.141 & SYN \\
\hline & 12 & $>512$ & 16 & 128 & 16 & 0.156 & SYN \\
\hline & 24 & $>512$ & 256 & 128 & 128 & $>1$ & $\mathrm{NI}$ \\
\hline \multirow[t]{2}{*}{ CA8 (S) } & 8 & $>512$ & 4 & 128 & 8 & 0.070 & SYN \\
\hline & 12 & $>512$ & 8 & 128 & 16 & 0.141 & SYN \\
\hline
\end{tabular}

Time indicates the incubation period of biofilm formation. SMICs were read as the lowest concentrations that produced a $50 \%$ reduction in growth compared with that of the drug-free control. MIC $C_{A}$, The MICs of fluconazole used alone; $M I C_{B}$. The MICs of licofelone used alone; $C_{A}$, The MICs of fluconazole combined with licofelone; $C_{B}$, The MICs of licofelone combined with fluconazole; IN, interaction; SYN, synergism; NI, no interaction. The FICl value is the median from three independent experiments. $\mathrm{FICl} \leq 0.5$ for synergism, $\mathrm{FICl}>4.0$ for antagonism and $0.5<\mathrm{FICl} \leq 4.0$ for no interaction.

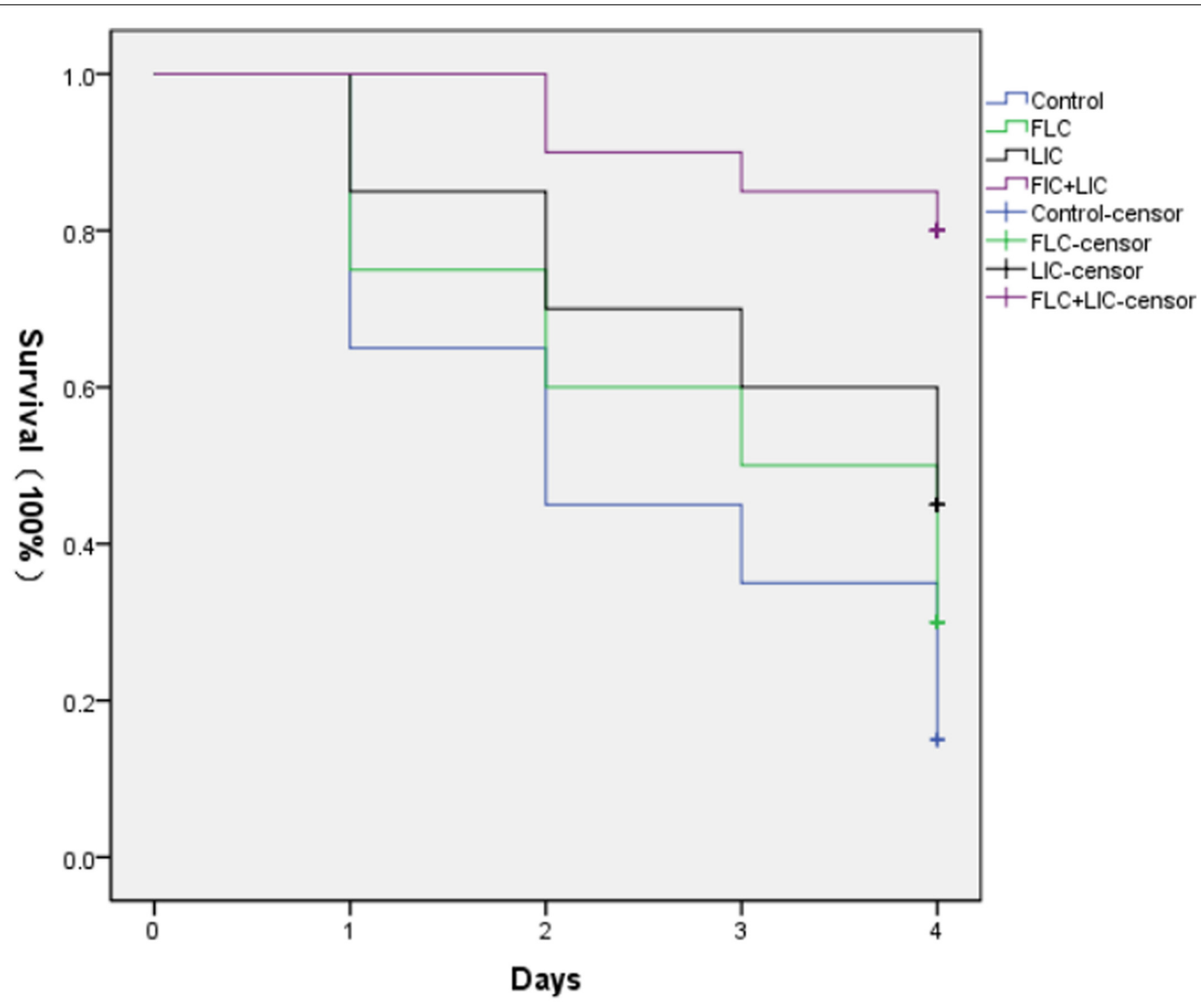

FIGURE 2 | Survival curve of different treatment on G. mellonella infected with resistant C. albicans (CA10). The concentration of yeast cells was $5 \times 10^{6}$ cells/larva. The curves were consisted growth control (PBS) group, fluconazole $(160 \mu \mathrm{g} / \mathrm{mL})$ group, licofelone $(80 \mu \mathrm{g} / \mathrm{mL})$ group and licofelone $(80 \mu \mathrm{g} / \mathrm{mL}) \mathrm{combined} \mathrm{with}$ fluconazole $(160 \mu \mathrm{g} / \mathrm{mL})$ group. These four curves were put in the same coordinate system to compare the survival rates. $* P<0.05$ compared to the control, fluconazole alone and licofelone alone group. The experiment was repeated on 3 independent occasions $(n=3)$. Values represent the means standard deviations from three replicates. 


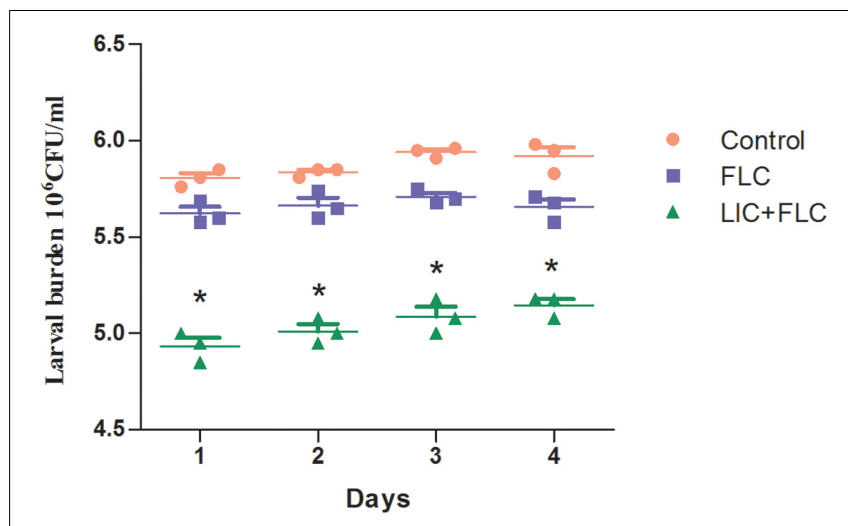

FIGURE 3 | Effect of drug combination on larval burdens of resistant C. albicans (CA10). All larvae were infected with $5 \times 10^{6}$ cells/larva C. albicans, the treatment consisted of control (PBS alone) group, fluconazole $(160 \mu \mathrm{g} / \mathrm{mL})$ alone group, and fluconazole $(160 \mu \mathrm{g} / \mathrm{mL})$ combined with licofelone $(80 \mu \mathrm{g} / \mathrm{mL})$ group. ${ }^{*} P<0.05$ compared to the control, and fluconazole alone group. The experiment was repeated on 3 independent occasions $(n=3)$. Values represent the means standard deviations from three replicates.

determined, and the melanization of $G$. mellonella infected with resistant C. albicans (CA10) was observed. The selection of drug concentration is not shown in this research. The results showed that after 2 days infection, all of the drug-treated groups showed attenuated melanization (Figure 2). Specifically, the twodrug combination group significantly reduced the melanization compared to the fluconazole group and was the highest survival rate $(P<0.05)$. After 4 day infection, the survival rate of larvae treated with fluconazole and combination group was higher than the growth control group by 1.3 and 4 -fold, respectively. The drug combination group was also highest $(P<0.05)$. The survival rate of larvae treated with licofelone alone group was a little higher than that of larvae treated with fluconazole group alone, that may be explained by the fact that the antifungal activity of licofelone alone is stronger than fluconazole.

\section{Fungal Burden Determination}

After 3 days of infection, the fungal burden was determined by recovering yeast cells from the larvae infected with resistant C. albicans (CA10). The number of CFUs in larvae were increased over the time of infection (Figure 3). Infected larvae that were treated with fluconazole $(160 \mu \mathrm{g} / \mathrm{mL})$ in combination with licofelone $(80 \mu \mathrm{g} / \mathrm{mL})$ exhibited lower fungal burden than fluconazole group. The two-drug combination significantly decreased CFU number by almost 4-fold compared to the control group $(P<0.05)$. The CFU number of the control group was also slightly decreased, which may be caused by hemocytes in larvae.

\section{Histopathology Study}

Histopathologic staining of larvae infected with resistant C. albicans (CA10) and treated with different drugs was performed at 3 day post infection. The differences in shape and cytoplasmic staining were detected. Both yeast and filament forms of C. albicans formed clusters in infected larvae. In the treatment with antifungal drugs, the formation of a majority of yeasts was decreased in the combination of fluconazole $(160 \mu \mathrm{g} / \mathrm{mL})$ and licofelone $(80 \mu \mathrm{g} / \mathrm{mL})$ group (Figures 4G,H). In addition, licofelone alone group (Figures $4 \mathrm{E}, \mathrm{F}$ ) decreased more yeast cells than fluconazole alone group (Figures 4C,D). The growth control (treatment with the PBS alone) group
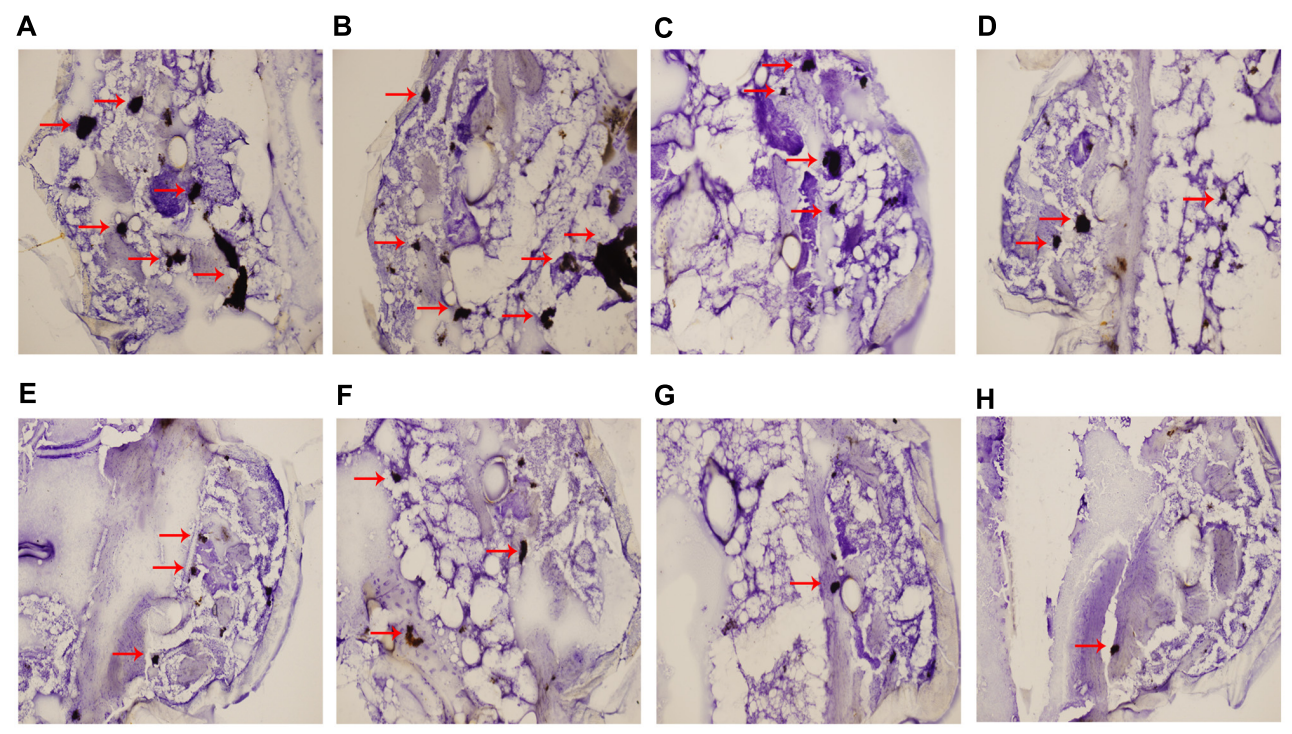

FIGURE 4 | Histopathology study of infected G. mellonella treated with different drugs. After $72 \mathrm{~h}$ of infection, larvae infected with $5 \times 10^{6}$ cells/larva of resistant C. albicans (CA10) were processed for histopathology as described. (A,B) Untreated controls group; (C,D) larvae treated with fluconazole (160 $\mu$ g/mL) group; (E,F) larvae treated with licofelone $(80 \mu \mathrm{g} / \mathrm{mL})$ group; $(\mathbf{G}, \mathbf{H})$ larvae treated with the combination of fluconazole $(160 \mu \mathrm{g} / \mathrm{mL})$ and licofelone $(80 \mu \mathrm{g} / \mathrm{mL}) \mathrm{group}$. The experiment was repeated on 3 independent occasions. 
TABLE 3 | Extracellular phospholipase activity of $C$. albicans treated with licofelone and fluconazole.

\begin{tabular}{lcc}
\hline Group $(\mu \mathbf{g} / \mathbf{m L})$ & $\begin{array}{c}\text { Precipitation } \\
\text { zone }\end{array}$ & $\begin{array}{c}\text { Phospholipase } \\
\text { activity }\end{array}$ \\
\hline Control & 0.61 & High \\
Fluconazole (1) & 0.62 & High \\
Licofelone (16) & 0.76 & High \\
Fluconazole + Licofelone (16) & $0.91^{a}$ & Very low \\
Licofelone (32) & $\mathrm{NZ}^{\mathrm{b}}$ & \\
Fluconazole + Licofelone (32) & $\mathrm{NZ}$ & \\
\hline
\end{tabular}

The precipitation zone represents the ratio of the diameter of the colony to the cloudy zone plus colony diameter. ${ }^{\mathrm{a}} \mathrm{P}<0.05$ compared to the control. ${ }^{\mathrm{b}} \mathrm{NZ}$, no zone of precipitation.

(Figures 4A,B) has higher levels of infection than any other group. The mean size of the infected areas was smaller in the combination group compared to the fluconazole group.

\section{Effect of Licofelone on Extracellular Phospholipases Activity of Resistant C. albicans}

The extracellular phospholipase activity of resistant C. albicans (CA10) was measured (Table 3). There were no obvious differences in average $\mathrm{Pz}$ between control group, fluconazole (1 $\mu \mathrm{g} / \mathrm{mL})$ group, and licofelone $(16 \mu \mathrm{g} / \mathrm{mL})$ group. The precipitation zone of the combination of fluconazole $(1 \mu \mathrm{g} / \mathrm{mL})$ and licofelone $(16 \mu \mathrm{g} / \mathrm{mL})$ group was significantly increased to 0.91 compared to the control group $(P<0.05)$. No precipitation zone was observed in licofelone $(32 \mu \mathrm{g} / \mathrm{mL}$ ) combined with fluconazole group $(P<0.05)$ and licofelone used alone $(32 \mu \mathrm{g} / \mathrm{mL})$ group.

\section{Effect of Fluconazole-Licofelone on SAP Gene Expression Levels}

To investigate the effects of licofelone and fluconazole on resistant C. albicans (CA10) secreted aspartyl proteinase activities, the expression of 4 SAP family genes was analyzed by RT-PCR. The results showed that both licofelone combined with fluconazole group and fluconazole alone group can downregulate the expression levels of SAP1,SAP2, SAP3, and SAP4 compared to the control group (Figure 5). The level of decreased expression in the combination group was more remarkable than the fluconazole alone group $(P<0.05)$. The expression level of $S A P 1$ in the fluconazole alone group was significantly decreased compared to the control group $(P<0.05)$. While the expression of SAP1 to SAP4 in licofelone alone group shows no obvious difference compared to the control group.

\section{Effect of Fluconazole-Licofelone on RAS1, CYR1, TPK2, EFG1, BCR1, ALS1, ALS3 and HWP1 Gene Expression Levels}

To further investigate the effects of licofelone and fluconazole on resistant C. albicans (CA10) biofilm development, the expression levels of 8 biofilm-related genes were analyzed by RT-PCR.

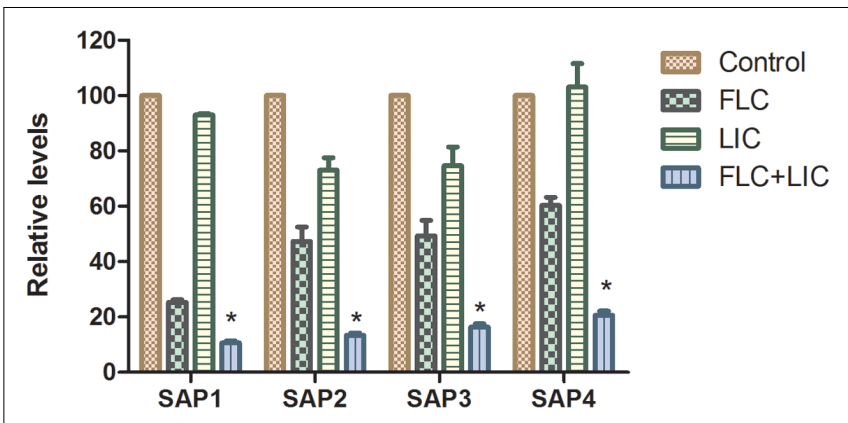

FIGURE 5 | Relative gene expression levels of SAP1, SAP2, SAP3, and SAP4 in resistant $C$. albicans (CA10). Cells were treated with fluconazole $(1 \mu \mathrm{g} / \mathrm{mL})$, licofelone $(16 \mu \mathrm{g} / \mathrm{mL})$ and their combination. Total RNA was extracted and reverse transcribed to cDNA for further real-time quantitative PCR to detect gene expression levels. ${ }^{*} P<0.05$ compared to the control, fluconazole alone and licofelone alone group. The experiment was repeated on 3 independent occasions $(n=3)$. Values represent the means standard deviations from three replicates.

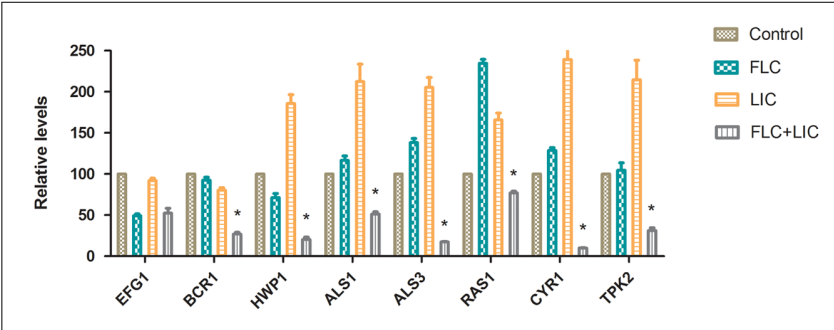

FIGURE 6 | Relative gene expression levels of RAS1, CYR1, TPK2, EFG1, BCR1, HWP1, ALS1 and ALS3 in resistant C. albicans (CA10). Cells were treated with fluconazole $(1 \mu \mathrm{g} / \mathrm{mL})$, licofelone $(16 \mu \mathrm{g} / \mathrm{mL})$ and their combination. Total RNA was extracted and reverse transcribed to cDNA for further real-time quantitative PCR to detect gene expression levels. ${ }^{*} P<0.05$ compared to the control, fluconazole alone and licofelone alone group. The experiment was repeated on 3 independent occasions $(n=3)$. Values represent the means standard deviations from three replicates.

The results showed that the combination of licofelone with fluconazole group down-regulated the RAS1, CYR1, TPK2, BCR1, HWP1, ALS1 and ALS3 expression in comparison with control group (Figure 6). The combination group significantly decreased the expression level of RAS1 (3-fold), CYR1 (10-fold), TPK2 (3-fold), BCR1 (4-fold), HWP1 (3-fold), ALS1 (2-fold) and ALS3 (8-fold) compared to the fluconazole group $(P<0.05)$. While the expression of RAS1, CYR1, TPK2, ALS1, ALS3, and HWP1 expression on licofelone alone were higher than fluconazole alone group. However, the down-regulation of EFG1 expression has no difference between the drug combination group and the fluconazole group $(P>0.05)$. In addition, both groups decreased EFG1 expression relative to the growth control group.

\section{Effect of Fluconazole-Licofelone on C. albicans Morphogenesis}

The hyphal formation was observed by fluorescence microscope. The images of resistant C. albicans (CA10) showed that the 


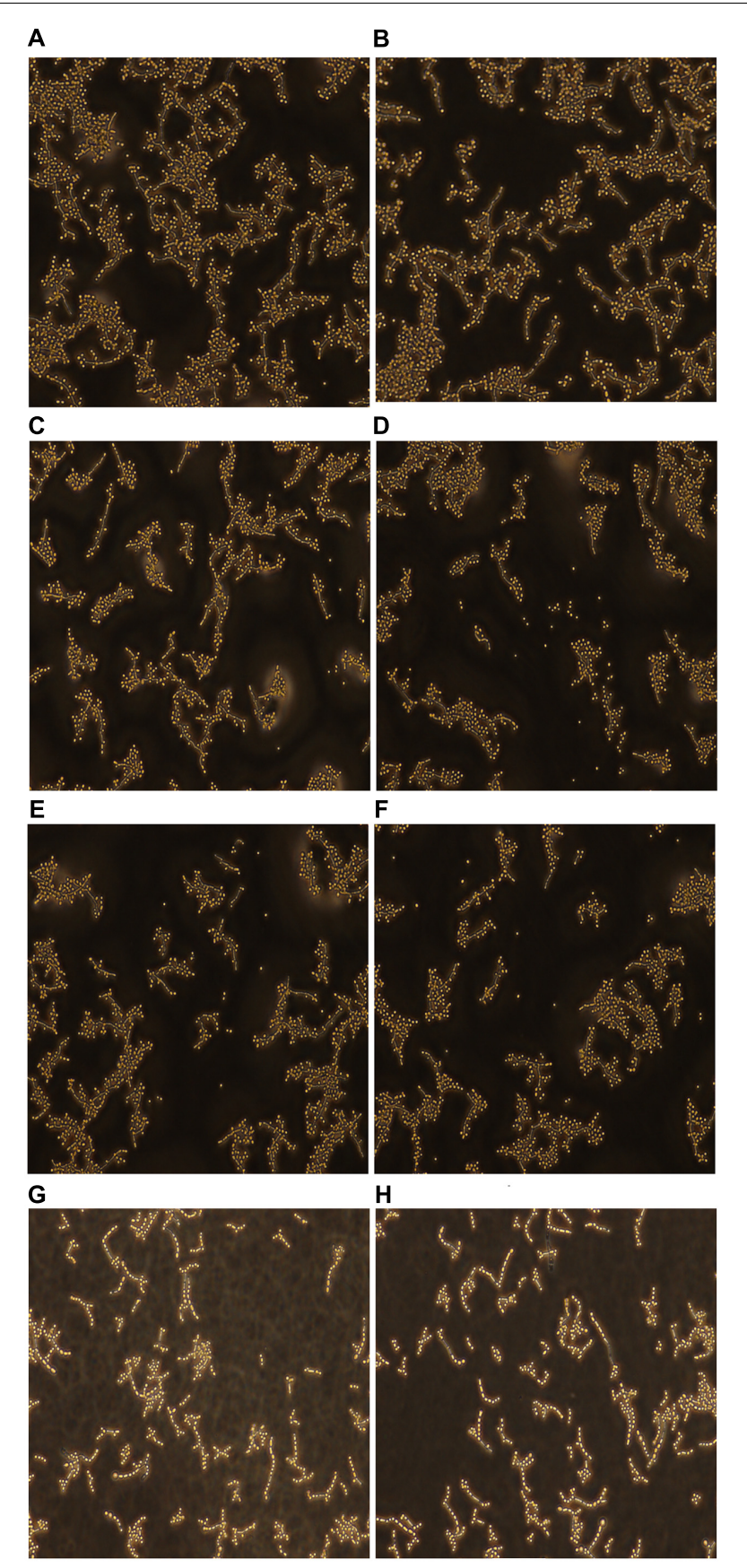

FIGURE 7 | Fluorescence microscope examined the yeast-filament transition of resistant C. albicans (CA10). After $24 \mathrm{~h}$ of incubation, C. albicans treated with different drugs as described. (A,B) Untreated controls group; (C,D) fluconazole treated $(1 \mu \mathrm{g} / \mathrm{mL})$ group; (E,F) licofelone treated $(16 \mu \mathrm{g} / \mathrm{mL})$ group; (G,H) the combination of fluconazole $(1 \mu \mathrm{g} / \mathrm{mL})$ and licofelone

$(16 \mu \mathrm{g} / \mathrm{mL})$ treated group. The experiment was repeated on 3 independent occasions.

filamentation was reduced with the presence of licofelone combined with fluconazole (Figures $\mathbf{7 G}, \mathbf{H}$ ) compared to the fluconazole treated group (Figures 7 C,D) and control group (Figures 7A,B). There were entirely yeast cells and no filaments

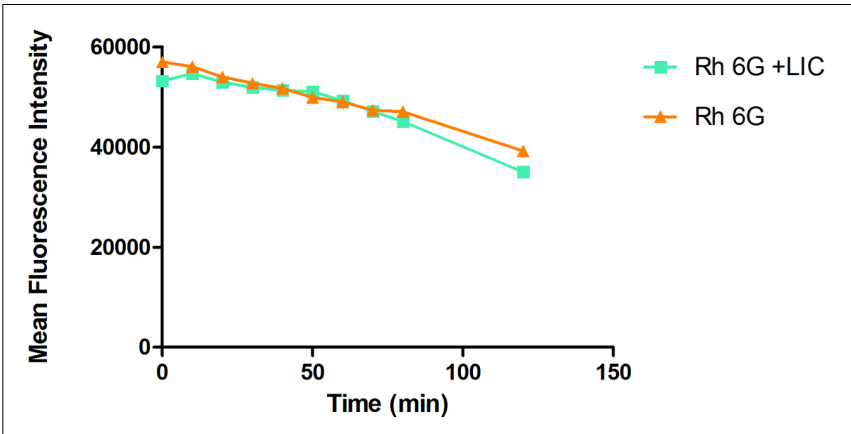

FIGURE 8 | The effect of licofelone on the efflux of Rh6G in resistant C. albicans. The efflux of Rh6G in the absence and presence of licofelone $(16 \mu \mathrm{g} / \mathrm{mL})$ were determined by a flow cytometer. MFls represent the intracellular Rh6G in C. albicans. ${ }^{*} P>0.05$ compared to the Rh6G alone group. The experiment was repeated on 3 independent occasions.

in the combination group. In the control group, there were a large area of hypha gather together, while in the fluconazole or licofelone alone group, there were still some hypha gathered, but it was much lesser than the control group. This may be caused that the two-drug combination can decrease the filament formation.

\section{Effect of Licofelone on Drug Efflux Pumps Activity of Resistant C. albicans}

The rhodamine $6 \mathrm{G}$ assay results showed that the licofelone group and the growth control group have the same decline tendency (Figure 8). No significant differences between groups were observed $(P>0.05)$.

\section{DISCUSSION}

Therapies such as the use of novel compounds combined with the azoles could be an effective solution for candida infections, as it can expand antibiotic spectrum, improve antifungal efficacy, and reduce side effects (Shrestha et al., 2015; Gu et al., 2016). Several in vitro and in vivo studies demonstrated that COX inhibitors, for instance, ibuprofen, aspirin, and indomethacin have certain antifungal activities by suppressing $C$. albicans $\mathrm{PGE}_{2}$ production and biofilm formation (Alem and Douglas, 2005; Bink et al., 2012; Liu et al., 2014). The combination of ibuprofen and fluconazole can enhance fluconazole susceptibly to $C$. albicans by decreasing the MIC of fluconazole (Costade-Oliveira et al., 2015). mPGES-1, as the terminal enzyme downstream of COX-2 can catalyze the $\mathrm{PGE}_{2}$ biosynthesis with fewer side effects, ideally not affecting the formation of other housekeeping PGs (Vidal et al., 2007; Koeberle et al., 2010). Various pharmacodynamic studies have confirmed that a novel dual mPGES-1/LOX inhibitor, licofelone was effective in many types of diseases and has anti-asthmatic and anticonvulsant effects (Rotondo et al., 2002; Kulkarni and Singh, 2007). The simultaneous inhibitions of both enzymes enable licofelone to have a superior anti-inflammatory effect and obviate the gastrointestinal side-effects compared to the NSAIDS. This better 
safety profile has been authenticated in healthy individuals (Charlier and Michaux, 2003; Bias et al., 2004). However, weather licofelone has the similar antifungal activity as COX inhibitor has not been elucidated. In this study, we first evaluated the effect of fluconazole combined with licofelone against resistant C. albicans in vitro, licofelone alone has a moderately great effect on resistant $C$. albicans: the MIC of licofelone alone against resistant C. albicans was $128 \mu \mathrm{g} / \mathrm{mL}$, and it can synergistically work with fluconazole: the $\mathrm{MIC}_{80}$ of fluconazole was decreased from 512 to $1 \mu \mathrm{g} / \mathrm{mL}$ when combined with licofelone $(16 \mu \mathrm{g} / \mathrm{mL})$, while the combination has little effect on sensitive $C$. albicans and non-albicans strains (Table 1). Secondly, the combined antifungal effect of fluconazole-licofelone against $C$. albicans biofilm cells was observed in different time point. The two-drug combination significantly reduced $C$. albicans biofilm formation over $12 \mathrm{~h}$, but after $24 \mathrm{~h}$, there was almost no anti-biofilm effect observed (Table 2). The C. albicans biofilm formation has three phases: adherence stage $(0-11 \mathrm{~h})$ in which the fungal pathogens adhere to the surface, development stage $(12-30 \mathrm{~h})$ in which the carbohydrate-rich extracellular matrix (ECM) are produced, and maturation stage $(31-72 \mathrm{~h})$ in which the biofilm structure is held together by an ECM. The resistance of biofilms to antimicrobial agents is often attributed to its failure to pass the biofilm matrix (Al-Fattani and Douglas, 2006). This may be the reason why the antifungal effect of the combination can only inhibit biofilm over the process of formation, but has no inhibiting effect on the mature biofilm. Further, for the future experiments, we will focus on the effect and antifungal mechanisms of resistant C. albicans.

In addition, G. mellonella model recently has been used to study fungal virulence and antifungal drug activity, since it has a similar immune response to mammals (Vilcinskas, 2011; Favre-Godal et al., 2014), and the correlation between virulence of $C$. albicans mutants in mice and $G$. mellonella model has been confirmed (Brennan et al., 2002). It is worth mentioning that, with these advantages and the low cost, lack of ethical concerns and easy manipulation, G. mellonella model has gained wide acknowledgment. As documented in our in vivo study, the combination of fluconazole with licofelone in G. mellonella infected model significantly improved the survival rate of larvae compared to the fluconazole treated group $(P<0.05)$. The death rate of the larvae is a dose dependent (Figure 2), as previously described (Scorzoni et al., 2013). To complement the studies in vivo, we further performed the fungal burden determination (Figure 3) and microscopic observation (Figure 4) in larvae after infection. Our results confirmed the correlation of the virulence with the degree of damage on the histological tissue of G. mellonella with fewer CFUs was observed in the combined group.

Candida albicans biofilm is a complex three-dimensional architecture with an abundant extracellular matrix. It is known to enhance the fungal resistance to most commonly used antifungal agent and the ability of cells to adhere is indispensable for all stages of C. albicans biofilm formation (Chandra et al., 2001; Nobile and Johnson, 2015). Earlier evidence only indicated that the effectiveness of COX inhibitors against $C$. albicans is based on their activity of inhibiting biofilm formation by decreasing $\mathrm{PGE}_{2}$ production. Here we investigated the further antifungal mechanisms of licofelone combined with fluconazole. $\mathrm{RAS} / \mathrm{cAMP} / \mathrm{PKA}$ pathway is important for C. albicans virulence by regulating hyphal growth (Rocha et al., 2001). In this pathway, the activation of Ras1 can lead to the generation of a CAMP signal that promotes PKA-mediated activation of the transcriptional regulator proteins EFG1 and BCR1, which that play an essential role in regulating the morphogenesis and expression level of cell wall-associated adhesion gene such as ALS1, ALS3, and HWP1 that are associated with morphogenetic response (Nobile and Mitchell, 2005). Our in vitro result showed that licofelone combined with fluconazole has great effects on inhibiting biofilm formation in different stages. Regarding how the drug combination influences the biofilm formation, the results showed that the combination has no influence on EFG1 expression level, but dramatically downregulated the expression of $B C R 1$ (Figure 6), suggesting that the possibility of drug combination against resistant C. albicans biofilm is through the regulation of the central regulator $B C R 1$, not by EFG1. We further examined the adhesionrelated genes $H W P 1, A L S 1$ and $A L S 3$ expression levels in the presence of the combination. We found that the expression level of those genes was decreased 3-fold, 2-fold, and 8-fold, respectively, compared to the fluconazole group $(P<0.05)$ (Figure 6). Mutational analysis indicated that strains lacking all functional HWP1, ALS1 and ALS3 alleles ( $h w p 1 \Delta / h w p 1 \Delta$ als $1 \Delta$ /als $1 \Delta$ als $3 \Delta /$ als $3 \Delta$ ) were not able to generate adherent cells in biofilm models (Nobile et al., 2008). Thus, our results demonstrated that the fluconazole combined with licofelone may reduce the biofilm formation of $C$. albicans by inhibiting adhesion, and this inhibition is partly due to the downregulation of biofilm cell wall adhesion-related genes ALS1, ALS3 and HWP1. These results were further confirmed by florescence microscope analysis. The two-drug combinationtreated strains produced a biofilm with only yeast cells and little filament, but the filamentation was more abundant with the presence of fluconazole group and the growth control group (Figure 7). Moreover, licofelone combined with fluconazole decreased the expression level of RAS1, CYR1 and TPK2, indicating that the inhibition of biofilm-specific related genes is probably through RAS/cAMP/PKA pathway (Figure 6). Previous studies have also shown that secreted aspartyl proteinase and phospholipases were believed to be important factors involved in the pathogenicity and virulence of C. albicans (Ghannoum, 2000; Feng et al., 2016). These hydrolytic enzymes were secreted by the fungus that lead to the colonization and infections (Nailis et al., 2010). Secreted aspartyl proteinases are related to the adhesion and hydrolytic activity in mucosal tissue (Ramage et al., 2012). The study by Mendes et al. has indicated that biofilms of C. albicans secreted more Saps than planktonic cells (Mendes et al., 2007), and Saps are known to be intrinsically associated with the hyphal phase of C. albicans (Chen et al., 2002; Felk et al., 2002). We also examined the SAP gene expression by RT-PCR. The combination of fluconazole and licofelone significantly down-regulated the SAP1-SAP4 expression levels compared to fluconazole group 
$(P<0.05)$ (Figure 5). In terms of extracellular phospholipase, the egg yolk agar plate assay showed that licofelone combined with fluconazole decreased the phospholipase activity at low concentration compared to the fluconazole group, and the inhibition effect was positively correlated to the drug concentration (Table 3). Furthermore, licofelone combined with fluconazole has no effect on the drug efflux pumps compared to the fluconazole group $(P>0.05)$ (Figure 8), thus the antifungal activity of the combination was irrelevant to reverse the mechanism of drug efflux. To our knowledge, the present study provides an substantial advance over recent studies of ours and in the field by first finding that the synergistic effect of licofelone combined with fluconazole against resistant $C$. albicans in both in vitro and in vivo. The underlying mechanisms are mainly explained by attenuation of virulence factor such as secreted aspartyl proteinase, reduction of extracellular phospholipase activity, and inhibition of the transition between yeast and hyphal growth forms, but not to affect the drug efflux pumps activity. These results indicate that licofelone could be a favorable antifungal agent and a promising synergist with fluconazole against resistant C. albicans, and more in-depth mechanisms needed to be elucidated.

\section{REFERENCES}

Alem, M. A., and Douglas, L. J. (2004). Effects of aspirin and other nonsteroidal anti-inflammatory drugs on biofilms and planktonic cells of Candida albicans. Antimicrob. Agents Chemother. 48, 41-47.

Alem, M. A., and Douglas, L. J. (2005). Prostaglandin production during growth of Candida albicans biofilms. J. Med. Microbiol. 54, 1001-1005.

Al-Fattani, M. A., and Douglas, L. J. (2006). Biofilm matrix of Candida albicans and Candida tropicalis: chemical composition and role in drug resistance. J. Med. Microbiol. 55, 999-1008.

Amorim-Vaz, S., Delarze, E., Ischer, F., Sanglard, D., and Coste, A. T. (2015). Examining the virulence of Candida albicans transcription factor mutants using Galleria mellonella and mouse infection models. Front. Microbiol. 6:367. doi: 10.3389/fmicb.2015.00367

Bertout, S., Dunyach, C., Drakulovski, P., Reynes, J., and Mallie, M. (2011). Comparison of the sensititre YeastOne(R) dilution method with the Clinical Laboratory Standards Institute (CLSI) M27-A3 microbroth dilution reference method for determining MIC of eight antifungal agents on 102 yeast strains. Pathol. Biol. 59, 48-51. doi: 10.1016/j.patbio.2010.07.020

Bias, P., Buchner, A., Klesser, B., and Laufer, S. (2004). The gastrointestinal tolerability of the LOX/COX inhibitor, licofelone, is similar to placebo and superior to naproxen therapy in healthy volunteers: results from a randomized, controlled trial. Am. J. Gastroenterol. 99, 611-618.

Bink, A., Kucharikova, S., Neirinck, B., Vleugels, J., Van Dijck, P., Cammue, B. P., et al. (2012). The nonsteroidal antiinflammatory drug diclofenac potentiates the in vivo activity of caspofungin against Candida albicans biofilms. J. Infect. Dis. 206, 1790-1797. doi: 10.1093/infdis/jis594

Braga-Silva, L. A., and Santos, A. L. (2011). Aspartic protease inhibitors as potential anti-Candida albicans drugs: impacts on fungal biology, virulence and pathogenesis. Curr. Med. Chem. 18, 2401-2419.

Brennan, M., Thomas, D. Y., Whiteway, M., and Kavanagh, K. (2002). Correlation between virulence of Candida albicans mutants in mice and Galleria mellonella larvae. FEMS Immunol. Med. Microbiol. 34, 153-157.

Bu, J., Zhao, J., and Liu, M. (2016). Expression stabilities of candidate reference genes for RT-qPCR in Chinese jujube (Ziziphus jujuba Mill.) under a variety of conditions. PLOS ONE 11:e0154212. doi: 10.1371/journal.pone. 0154212

\section{AUTHOR CONTRIBUTIONS}

XL, TL, DW, WS, YY, JL, and SS performed the experiments. XL and SS designed the research. XL analyzed the data and wrote the paper. All authors approved the manuscript for publication.

\section{ACKNOWLEDGMENTS}

This work was supported by a grant from the Department of Science and Technology of Shandong Province of China (2013GSF11848, 2016GSF201187). The authors would like to thank Translational Medicine Research Centre in Qianfoshan Hospital Affiliated to Shandong University, China for laboratory assistance; and all members of the anti-fungal resistance study group for support and valuable opinions.

\section{SUPPLEMENTARY MATERIAL}

The Supplementary Material for this article can be found online at: https://www.frontiersin.org/articles/10.3389/fmicb. 2017.02101/full\#supplementary-material

Cao, S., Zhang, X., Ye, N., Fan, X., Mou, S., Xu, D., et al. (2012). Evaluation of putative internal reference genes for gene expression normalization in Nannochloropsis sp. by quantitative real-time RT-PCR. Biochem. Biophys. Res. Commun. 424, 118-123. doi: 10.1016/j.bbrc.2012.06.086

Carrillo-Munoz, A. J., Giusiano, G., Ezkurra, P. A., and Quindos, G. (2006). Antifungal agents: mode of action in yeast cells. Rev. Esp. Quimioter. 19, $130-139$.

Chandra, J., Kuhn, D. M., Mukherjee, P. K., Hoyer, L. L., Mccormick, T., and Ghannoum, M. A. (2001). Biofilm formation by the fungal pathogen Candida albicans: development, architecture, and drug resistance. J. Bacteriol. 183, 5385-5394.

Charlier, C., and Michaux, C. (2003). Dual inhibition of cyclooxygenase-2 (COX-2) and 5-lipoxygenase (5-LOX) as a new strategy to provide safer non-steroidal anti-inflammatory drugs. Eur. J. Med. Chem. 38, 645-659.

Chen, T. C., Chen, Y. H., Chen, Y. C., and Lu, P. L. (2012). Fluconazole exposure rather than clonal spreading is correlated with the emergence of Candida glabrata with cross-resistance to triazole antifungal agents. Kaohsiung J. Med. Sci. 28, 306-315. doi: 10.1016/j.kjms.2011.11.011

Chen, Y. C., Wu, C. C., Chung, W. L., and Lee, F. J. (2002). Differential secretion of Sap4-6 proteins in Candida albicans during hyphae formation. Microbiology $148,3743-3754$.

Clements, J. S. Jr., and Peacock, J. E. Jr. (1990). Amphotericin B revisited: reassessment of toxicity. Am. J. Med. 88, 22N-27N.

Costa-de-Oliveira, S., Miranda, I. M., Silva-Dias, A., Silva, A. P., Rodrigues, A. G., and Pina-Vaz, C. (2015). Ibuprofen potentiates the in vivo antifungal activity of fluconazole against Candida albicans murine infection. Antimicrob. Agents Chemother. 59, 4289-4292. doi: 10.1128/AAC.05056-14

Cui, J., Ren, B., Tong, Y., Dai, H., and Zhang, L. (2015). Synergistic combinations of antifungals and anti-virulence agents to fight against Candida albicans. Virulence 6, 362-371. doi: 10.1080/21505594.2015.1039885

de Quadros, A. U., Bini, D., Pereira, P. A., Moroni, E. G., and Monteiro, M. C. (2011). Antifungal activity of some cyclooxygenase inhibitors on Candida albicans: PGE2-dependent mechanism. Folia Microbiol. 56, 349-352.

Favre-Godal, Q., Dorsaz, S., Queiroz, E. F., Conan, C., Marcourt, L., Wardojo, B. P., et al. (2014). Comprehensive approach for the detection of antifungal compounds using a susceptible strain of Candida albicans and confirmation of 
in vivo activity with the Galleria mellonella model. Phytochemistry 105, 68-78. doi: 10.1016/j.phytochem.2014.06.004

Felk, A., Kretschmar, M., Albrecht, A., Schaller, M., Beinhauer, S., Nichterlein, T., et al. (2002). Candida albicans hyphal formation and the expression of the Efg1regulated proteinases Sap4 to Sap6 are required for the invasion of parenchymal organs. Infect. Immun. 70, 3689-3700.

Feng, W., Yang, J., Pan, Y., Xi, Z., Qiao, Z., and Ma, Y. (2016). The correlation of virulence, pathogenicity, and itraconazole resistance with SAP activity in Candida albicans strains. Can. J. Microbiol. 62, 173-178. doi: 10.1139/cjm2015-0457

Garcia-Vidal, C., Viasus, D., and Carratala, J. (2013). Pathogenesis of invasive fungal infections. Curr. Opin. Infect. Dis. 26, 270-276. doi: 10.1097/QCO. ob013e $32835 \mathrm{fb} 920$

Ghannoum, M. A. (2000). Potential role of phospholipases in virulence and fungal pathogenesis. Clin. Microbiol. Rev. 13, 122-143.

Gu, W., Guo, D., Zhang, L., Xu, D., and Sun, S. (2016). The synergistic effect of azoles and fluoxetine against resistant Candida albicans strains is attributed to attenuating fungal virulence. Antimicrob. Agents Chemother. 60, 6179-6188. doi: 10.1128/AAC.03046-15

Harizi, H., Corcuff, J. B., and Gualde, N. (2008). Arachidonic-acid-derived eicosanoids: roles in biology and immunopathology. Trends Mol. Med. 14, 461-469. doi: 10.1016/j.molmed.2008.08.005

Hogan, D. A., and Sundstrom, P. (2009). The Ras/cAMP/PKA signaling pathway and virulence in Candida albicans. Fut. Microbiol. 4, 1263-1270. doi: 10.2217/ fmb.09.106

Hube, B., Hess, D., Baker, C. A., Schaller, M., Schafer, W., and Dolan, J. W. (2001). The role and relevance of phospholipase D1 during growth and dimorphism of Candida albicans. Microbiology 147, 879-889.

Kalo-Klein, A., and Witkin, S. S. (1990). Prostaglandin E2 enhances and gamma interferon inhibits germ tube formation in Candida albicans. Infect. Immun. 58, 260-262.

Katragkou, A., Mccarthy, M., Alexander, E. L., Antachopoulos, C., Meletiadis, J., Jabra-Rizk, M. A., et al. (2015). In vitro interactions between farnesol and fluconazole, amphotericin B or micafungin against Candida albicans biofilms. J. Antimicrob. Chemother. 70, 470-478. doi: 10.1093/jac/ dku374

Koeberle, A., Rossi, A., Zettl, H., Pergola, C., Dehm, F., Bauer, J., et al. (2010). The molecular pharmacology and in vivo activity of 2-(4-chloro-6(2,3-dimethylphenylamino)pyrimidin-2-ylthio)octanoic acid (YS121), a dual inhibitor of microsomal prostaglandin E2 synthase-1 and 5-lipoxygenase. J. Pharmacol. Exp. Ther. 332, 840-848. doi: 10.1124/jpet.109.160663

Koeberle, A., Siemoneit, U., Buhring, U., Northoff, H., Laufer, S., Albrecht, W., et al. (2008). Licofelone suppresses prostaglandin E2 formation by interference with the inducible microsomal prostaglandin E2 synthase-1. J. Pharmacol. Exp. Ther. 326, 975-982. doi: 10.1124/jpet.108.139444

Krezdorn, J., Adams, S., and Coote, P. J. (2014). A Galleria mellonella infection model reveals double and triple antibiotic combination therapies with enhanced efficacy versus a multidrug-resistant strain of Pseudomonas aeruginosa. J. Med. Microbiol. 63, 945-955. doi: 10.1099/jmm.0.074245-0

Kulkarni, S. K., and Singh, V. P. (2007). Licofelone-a novel analgesic and antiinflammatory agent. Curr. Top. Med. Chem. 7, 251-263.

Kuykendall, R. J., and Lockhart, S. R. (2016). Microbroth dilution susceptibility testing of Candida species. Methods Mol. Biol. 1356, 173-181. doi: 10.1007/9781-4939-3052-4_13

Liu, S., Hou, Y., Chen, X., Gao, Y., Li, H., and Sun, S. (2014). Combination of fluconazole with non-antifungal agents: a promising approach to cope with resistant Candida albicans infections and insight into new antifungal agent discovery. Int. J. Antimicrob. Agents 43, 395-402. doi: 10.1016/j.ijantimicag. 2013.12.009

Liu, X., Wang, D., Yu, C., Li, T., Liu, J., and Sun, S. (2016). Potential antifungal targets against a Candida biofilm based on an enzyme in the arachidonic acid cascade-a review. Front. Microbiol. 7:1925. doi: 10.3389/fmicb.2016. 01925

Lockhart, S. R., Bolden, C. B., Iqbal, N., and Kuykendall, R. J. (2011). Validation of 24-hour flucytosine MIC determination by comparison with 48-hour determination by the Clinical and Laboratory Standards Institute M27-A3 broth microdilution reference method. J. Clin. Microbiol. 49, 4322-4325. doi: 10.1128/JCM.05479-11
Mendes, A., Mores, A. U., Carvalho, A. P., Rosa, R. T., Samaranayake, L. P., and Rosa, E. A. (2007). Candida albicans biofilms produce more secreted aspartyl protease than the planktonic cells. Biol. Pharm. Bull. 30, 1813-1815.

Mylonakis, E., Moreno, R., El Khoury, J. B., Idnurm, A., Heitman, J., Calderwood, S. B., et al. (2005). Galleria mellonella as a model system to study Cryptococcus neoformans pathogenesis. Infect. Immun. 73, 3842-3850.

Nailis, H., Kucharikova, S., Ricicova, M., Van Dijck, P., Deforce, D., Nelis, H., et al. (2010). Real-time PCR expression profiling of genes encoding potential virulence factors in Candida albicans biofilms: identification of modeldependent and -independent gene expression. BMC Microbiol. 10:114. doi: 10.1186/1471-2180-10-114

Nett, J. E., and Andes, D. R. (2016). Antifungal agents: spectrum of activity, pharmacology, and clinical indications. Infect. Dis. Clin. North Am. 30, 51-83. doi: $10.1016 /$ j.idc.2015.10.012

Niewerth, M., and Korting, H. C. (2001). Phospholipases of Candida albicans. Mycoses 44, 361-367.

Nobile, C. J., and Johnson, A. D. (2015). Candida albicans biofilms and human disease. Annu. Rev. Microbiol. 69, 71-92.

Nobile, C. J., and Mitchell, A. P. (2005). Regulation of cell-surface genes and biofilm formation by the C. albicans transcription factor Bcr1p. Curr. Biol. 15, $1150-1155$.

Nobile, C. J., Schneider, H. A., Nett, J. E., Sheppard, D. C., Filler, S. G., Andes, D. R., et al. (2008). Complementary adhesin function in C. albicans biofilm formation. Curr. Biol. 18, 1017-1024. doi: 10.1016/j.cub.2008.06.034

Noverr, M. C., Phare, S. M., Toews, G. B., Coffey, M. J., and Huffnagle, G. B. (2001). Pathogenic yeasts Cryptococcus neoformans and Candida albicans produce immunomodulatory prostaglandins. Infect. Immun. 69, 2957-2963.

Odds, F. C. (2003). Synergy, antagonism, and what the chequerboard puts between them. J. Antimicrob. Chemother. 52:1.

Payandemehr, B., Khoshneviszadeh, M., Varastehmoradi, B., Gholizadeh, R., Bahremand, T., Attar, H., et al. (2015). A COX/5-LOX inhibitor licofelone revealed anticonvulsant properties through iNOS diminution in mice. Neurochem. Res. 40, 1819-1828. doi: 10.1007/s11064-015-1669-z

Pfaller, M. A., Rhomberg, P. R., Messer, S. A., Jones, R. N., and Castanheira, M. (2015). Isavuconazole, micafungin, and 8 comparator antifungal agents' susceptibility profiles for common and uncommon opportunistic fungi collected in 2013: temporal analysis of antifungal drug resistance using CLSI species-specific clinical breakpoints and proposed epidemiological cutoff values. Diagn. Microbiol. Infect. Dis. 82, 303-313. doi: 10.1016/j.diagmicrobio. 2015.04.008

Pierce, C. G., Chaturvedi, A. K., Lazzell, A. L., Powell, A. T., Saville, S. P., Mchardy, S. F., et al. (2015). A novel small molecule inhibitor of Candida albicans biofilm formation, filamentation and virulence with low potential for the development of resistance. NPJ Biofilms Microbiomes 1, 15012.

Price, M. F., Wilkinson, I. D., and Gentry, L. O. (1982). Plate method for detection of phospholipase activity in Candida albicans. Sabouraudia 20, 7-14.

Ramage, G., Coco, B., Sherry, L., Bagg, J., and Lappin, D. F. (2012). In vitro Candida albicans biofilm induced proteinase activity and SAP8 expression correlates with in vivo denture stomatitis severity. Mycopathologia 174, 11-19. doi: 10.1007/s11046-012-9522-2

Rocha, C. R., Schroppel, K., Harcus, D., Marcil, A., Dignard, D., Taylor, B. N., et al. (2001). Signaling through adenylyl cyclase is essential for hyphal growth and virulence in the pathogenic fungus Candida albicans. Mol. Biol. Cell 12, 3631-3643.

Rotondo, S., Dell'elba, G., Krauze-Brzosko, K., Manarini, S., Martelli, N., Pecce, R., et al. (2002). Licofelone, a dual lipoxygenase-cyclooxygenase inhibitor, downregulates polymorphonuclear leukocyte and platelet function. Eur. J. Pharmacol. 453, 131-139.

Rusu, E., Radu-Popescu, M., Pelinescu, D., and Vassu, T. (2014). Treatment with some anti-inflammatory drugs reduces germ tube formation in Candida albicans strains. Braz. J. Microbiol. 45, 1379-1383.

Sagatova, A. A., Keniya, M. V., Wilson, R. K., Monk, B. C., and Tyndall, J. D. (2015). Structural insights into binding of the antifungal drug fluconazole to Saccharomyces cerevisiae lanosterol 14alpha-demethylase. Antimicrob. Agents Chemother. 59, 4982-4989. doi: 10.1128/AAC.00925-15

Scorzoni, L., De Lucas, M. P., Mesa-Arango, A. C., Fusco-Almeida, A. M., Lozano, E., Cuenca-Estrella, M., et al. (2013). Antifungal efficacy during Candida krusei infection in non-conventional models correlates with the yeast 
in vitro susceptibility profile. PLOS ONE 8:e60047. doi: 10.1371/journal.pone. 0060047

Shrestha, S. K., Fosso, M. Y., and Garneau-Tsodikova, S. (2015). A combination approach to treating fungal infections. Sci. Rep. 5:17070. doi: 10.1038/srep 17070

Sun, L. M., Liao, K., Liang, S., Yu, P. H., and Wang, D. Y. (2015). Synergistic activity of magnolol with azoles and its possible antifungal mechanism against Candida albicans. J. Appl. Microbiol. 118, 826-838. doi: 10.1111/jam. 12737

Sun, W., Wang, D., Yu, C., Huang, X., Li, X., and Sun, S. (2017). Strong synergism of dexamethasone in combination with fluconazole against resistant Candida albicans mediated by inhibiting drug efflux and reducing virulence. Int. J. Antimicrob. Agents 50, 399-405. doi: 10.1016/j.ijantimicag.2017.03.015

Vidal, C., Gomez-Hernandez, A., Sanchez-Galan, E., Gonzalez, A., Ortega, L., Gomez-Gerique, J. A., et al. (2007). Licofelone, a balanced inhibitor of cyclooxygenase and 5-lipoxygenase, reduces inflammation in a rabbit model of atherosclerosis. J. Pharmacol. Exp. Ther. 320, 108-116.

Vilcinskas, A. (2011). Insects emerge as valuable model hosts to explore virulence. Virulence 2, 376-378.
Wayn, E. P. (2008). Reference Method for Broth Dilution Antifungal Susceptibility Testing of Yeasts, 3rd Edn. Wayne, PA: Clinical and Laboratory Standards Institute, 28.

Yun, B., Lee, H., Jayaraja, S., Suram, S., Murphy, R. C., and Leslie, C. C. (2016). Prostaglandins from cytosolic phospholipase A2alpha/cyclooxygenase1 pathway and mitogen-activated protein kinases regulate gene expression in Candida albicans-infected macrophages. J. Biol. Chem. 291, 7070-7086. doi: $10.1074 /$ jbc.M116.714873

Conflict of Interest Statement: The authors declare that the research was conducted in the absence of any commercial or financial relationships that could be construed as a potential conflict of interest.

Copyright $(2) 2017$ Liu, Li, Wang, Yang, Sun, Liu and Sun. This is an open-access article distributed under the terms of the Creative Commons Attribution License (CC BY). The use, distribution or reproduction in other forums is permitted, provided the original author(s) or licensor are credited and that the original publication in this journal is cited, in accordance with accepted academic practice. No use, distribution or reproduction is permitted which does not comply with these terms. 